\title{
The Impact of School Resources on Student Attainment: A Multilevel Simultaneous Equation Modelling Approach
}

\author{
Fiona Steele* \\ Graduate School of Education \\ University of Bristol
}

\author{
Anna Vignoles and Andrew Jenkins \\ Bedford Group for Lifecourse and Statistical Studies \\ Institute of Education, University of London
}

\section{Summary}

Improving educational achievement in UK schools is a priority, and of particular concern is the low achievement of specific groups, such as those from lower socio-economic backgrounds. An obvious question is whether we should be improving the outcomes of these students by spending more on their education. The literature on the effect of educational spending on pupil achievement has a number of methodological difficulties, in particular the endogeneity of school resource levels, and the intra-school correlations in student responses. In this paper, we adopt a multilevel simultaneous equation modelling approach to assess the impact of school resources on student attainment at age 14. This paper is the first to apply a simultaneous equation model to estimate the impact of school resources on pupil achievement, using the newly available National Pupil Database (NPDB).

Keywords: education production function, multilevel simultaneous equation model

*Address for correspondence: Fiona Steele, Graduate School of Education, University of Bristol, 35 Berkeley Square, Bristol BS8 1JA, Email: f.steele@ioe.ac.uk 


\section{Introduction}

For policy-makers and parents alike, improving educational achievement in UK schools is a policy priority. There is certainly an economic imperative to raise educational achievement, given that an additional year of education in the OECD area is estimated to increase economic output by between 3 and 6 percent (OECD, 2004). Currently, the UK spends around 5 per cent of its annual Gross Domestic Product on education, including primary, secondary and postsecondary (compared to an OECD mean of 5.6 per cent), and expenditure has been increasing since the mid 1990s. Nonetheless, spending in UK secondary schools (US\$5933) is below the OECD mean of US\$6510 (OECD, 2004). However, lower expenditure does not necessarily mean lower achievement, at least in aggregate. The UK, along with countries such as Australia, Finland, Ireland and Korea, spends a lower than average amount on secondary schooling but its students perform relatively well in international tests of student achievement, such as the Programme for International Student Assessment (Machin and Vignoles, 2005). An obvious policy question is therefore whether an increase in per pupil expenditure on education, or a reduction in the average pupil-teacher ratio in schools, is a viable means of improving pupil attainment across the board. There are a number of reasons why this may not in fact be a feasible policy option. One possibility that is much discussed in the literature, and which has hugely important policy implications, is that state schools are inefficient in their use of resources, so that higher spending schools do not systematically have better pupil outcomes (Hanushek, 1997). This paper not only aims to provide empirical evidence to guide policy-makers on this issue, but also seeks to overcome some important methodological difficulties that plague many of the previous studies in this area of research.

Another policy issue of particular concern in the UK is the low achievement of specific groups of students, such as those from lower socio-economic backgrounds and certain gender/ ethnic groups. Again, an obvious question is whether we should be improving the outcomes of these students by spending more on their education. This research question is explored in our previous work on this issue (Levačić et al., 2005), which used an instrumental variable approach to examine the relationship between school resourcing levels and the attainment of different subgroups of English pupils. Here, we adopt a somewhat different methodology (a multilevel simultaneous equation model) to try to accurately ascertain the 
direction and magnitude of any links between school resources ${ }^{1}$ and the mean educational attainment of pupils in England.

There is a large and controversial literature analysing the relationship between school resourcing levels and pupil achievement, dating back to the pioneering work by Coleman et al. (1966). Much of the US evidence suggests a weak and somewhat inconsistent relationship between school resources and pupil achievement. (Burtless, 1996; Hanushek, 1997). However, this view has been disputed by some, including Lane et al. (1996) and Krueger (2003).

Largely, the controversy in this literature centres on the extent to which studies that show no significant relationship between school resources and pupil achievement are able to overcome a number of methodological difficulties. One major methodological difficulty in the literature is the problem of the endogeneity of school resources due to the non-random way in which funds are allocated across schools. In the UK, schools with higher concentrations of lower attaining students receive more funding per student. If this feature of resource allocation is ignored, a true positive effect of increasing resources will be understated. In addition, there may be unobserved characteristics of schools, and also of local education authorities (LEAs), which influence both resource allocation and student attainment. For example, one factor in the funding allocation formula used by LEAs is the proportion of socially disadvantaged students in a school, which is also associated with student outcomes. In the absence of adequate controls for social background, a true positive resource effect will be diluted or may even appear negative.

There are a number of potential methods that might be used to overcome this endogeneity problem, including random assignment. For example, the Tennessee STAR class size experiment randomly allocated children in primary school to small and large class sizes. Results from STAR suggest that smaller classes do increase student attainment and that gains persist to the school leaving age and college (Krueger and Whitmore, 2001). Another method that is used to overcome the endogeneity problem is a natural experiment. The international literature using natural experiments, such as rules on class size, or court-imposed policies to raise spending on schools, has produced mixed results. Angrist and Lavy (1999) and Jepson

\footnotetext{
${ }^{1}$ Per student expenditure and the school pupil-teacher ratio.
} 
and Rivkin (2002) found positive effects of smaller class size on student attainment for Israel and California respectively. However Hoxby (2000) found no effect of class size and Dobbelsteen et al. (2002), instrumenting on teacher allocation rules, reported a significant positive effect of larger class size on attainment for the Netherlands.

Yet another approach to tackling endogeneity is to include a large number of control variables to reduce the possibility of covariance between resources and any unobserved variables that affect attainment. For example, Wilson (2000) using extensive data on family and neighbourhoods for the US found school spending to be positively related to high school graduation and years of schooling. Another method tried by Hakkinen et al. (2003) is using panel data over a number of years to difference out school and district effects. They find no effects on exam scores in Finnish upper secondary schools of changes in per student spending from 1990-98.

It is fair to say, however, that the vast majority of school resource effect studies have not been able to address the endogeneity problem. This is certainly the case in the UK (Levačić and Vignoles, 2002). UK studies that have made some attempt to address endogeneity have generally found small but statistically significant positive effects from school resource variables on educational outcomes. (Dearden et al., 2001; Dolton and Vignoles, 2000; Dustmann et al., 2003; Iacovou, 2002).

Endogeneity issues are not the only methodological difficulty in this literature. Another important methodological issue to be considered is the intra-school correlations in student responses. The need to control for clustering in the analysis of hierarchically structured data is well known (see, e.g., Goldstein, 2003). One consequence of ignoring clustering is the underestimation of standard errors due to the decrease in the effective sample size, and in general the underestimation is most severe for explanatory variables defined at the cluster level. In the present case, it is especially important to adjust for clustering because the variables of major interest, measures of school resources, are school-level characteristics.

In this paper, we adopt a multilevel simultaneous equation modelling approach to assess the impact of school resources on student attainment at age 14. A multilevel model is used to allow for clustering of student outcomes by school and LEA, and clustering of school 
resources by LEA. A simultaneous equation model is used to adjust for the endogeneity of school resource allocation. In this approach, student attainment and a measure of school resources are treated as a bivariate response. A multilevel model is defined for each response with LEA and school level random effects included in each; these random effects may be correlated across the attainment and resource equations, which allows explicitly for correlation between the unobserved LEA and school characteristics that influence each response. Our approach differs from the instrumental variable (IV) method traditionally used to account for endogeneity in the assumptions made about the level at which selection effects operate. The standard approach involves estimating equations for the outcome of interest and the endogenous regressor, either simultaneously or more commonly in two stages, but the equations are linked via correlated residuals defined at the lowest level of observation, in this case the student. This method may be inappropriate on two counts: first, it incorrectly treats school resources as a student-level variable and, second, it does not recognise that endogeneity arises due to correlation between unobservables at the school or LEA level rather than at the student level.

This paper is the first to apply a simultaneous equation model to estimate the impact of school resources on pupil achievement, using the newly available National Pupil Database. The NPDB contains information on the characteristics and achievement of every pupil in an English school, as well as characteristics of the schools themselves. The NPDB is supplemented by information on schools' levels of resourcing, derived from data submitted to the Department for Education and Skills by local education authorities. NPDB provides information on individual students' attainment at age 14 (Key Stage 3) in 2003 and their attainment at age 11 (Key Stage 2) in 2000, enabling us to control for prior attainment in our model. Previous work in this area has been restricted to using either more aggregated data (school or LEA level data) or relying on the National Child Development Study data set that, whilst rich, is somewhat dated in terms of providing empirical evidence to inform education policy today (its sample consists of a cohort born in 1958).

\section{Background on the Secondary Education System in England}

In England, educational spending on both primary and secondary schooling is administered by 150 local education authorities (LEAs), which are under local government control. However, in the years for which our study data were collected, the majority of the money for 
education came from central government via a block grant ${ }^{2}$ to these LEAs for all local services. LEAs could spend this grant more or less according to their own priorities, and decide to spend more or less than the amount notionally allocated per pupil in the block grant. The amount of money received by a particular LEA from central government nominally for education, which until recently was known as the Education Standard Spending Assessment $(\mathrm{SSA})^{3}$, depends on a number of factors that influence the expected educational costs in an LEA. For example, the education SSA takes account of student numbers, socio-economic factors (e.g. the number of immigrants in the area, the proportion of the local population in lower socio-economic groups and the numbers of families on state benefit), density of population and cost of living in the area.

The fact that socio-economic factors partly determine the SSA implies that in the UK greater school resources are allocated to areas of greater educational need. This is reinforced by the fact that the actual block grant given to LEAs takes account of the potential in the LEA to raise local tax for educational spending. Thus prosperous areas tend to receive less from central government since they can potentially raise more revenue from local taxation. The fact that LEAs have some discretion over how to spend the grant they receive ${ }^{4}$ again reinforces the point that endogeneity is likely to be a problem in any analysis of the influence of educational expenditure on pupil achievement.

\section{Methods}

\subsection{The standard multilevel modelling approach}

Denote by $y_{i j k}$ the attainment at age 14 in maths, English or science of student $i \quad(i=1, \ldots$, $\left.n_{j k} ; n=\sum_{j, k} n_{j k}\right)$ in school $j\left(j=1, \ldots, J_{k} ; J=\sum_{k} J_{k}\right)$ in LEA $k(k=1, \ldots, K)$. The standard approach to modelling attainment, allowing for clustering at the school and LEA levels, would be to fit a three-level random effects model. The simplest such model allows the regression intercept to vary randomly across schools and LEAs:

\footnotetext{
${ }^{2}$ Revenue Support Grant.

${ }^{3}$ Now the Education Formula Spending Share.

${ }^{4}$ Thus actual expenditure per pupil varies systematically by LEA, depending partly on the political party in control of the local authority and their educational priorities.
} 
$y_{i j k}=\boldsymbol{\alpha}^{T} \mathbf{x}_{i j k}+\beta z_{j k}+v_{k}^{(y)}+u_{j k}^{(y)}+e_{i j k}$

where $\mathbf{x}_{i j k}$ is a vector of explanatory variables defined at the student, school or LEA level, $\boldsymbol{\alpha}$ is a vector of associated coefficients, $z_{j k}$ is a measure of school resources with coefficient $\beta$, and $v_{k}^{(y)}, u_{j k}^{(y)}$ and $e_{i j k}$ are residuals for LEAs, schools and students respectively. Typically, the residuals are assumed to be normally distributed: $v_{k}^{(y)} \sim N\left(0, \sigma_{v(y)}^{2}\right)$, $u_{j k}^{(y)} \sim N\left(0, \sigma_{u(y)}^{2}\right)$ and $e_{i j k} \sim N\left(0, \sigma_{e(y)}^{2}\right)$.

A further assumption of the standard multilevel model is that the residuals at each level are uncorrelated with the predictor variables $\mathbf{x}_{i j k}$ and $z_{j k}$. For the reasons given in Sections 1 and 2 above, however, this assumption is questionable because the mechanisms by which resources are allocated to schools are likely to be related to the unobserved determinants of student attainment; these unobserved factors may be acting at the school or LEA level or both, leading to nonzero correlations between $z_{j k}$ and either or both of $u_{j k}^{(y)}$ and $v_{k}^{(y)}$.

\subsection{A simultaneous equations model for attainment and resource allocation}

One way to allow for the potential endogeneity of resources $Z_{j k}$ with respect to attainment $y_{i j k}$ is to model the resource allocation process jointly with attainment. A two-level random intercept model for school resources is

$Z_{j k}=\gamma^{T} \mathbf{w}_{j k}+v_{k}^{(z)}+u_{j k}^{(z)}$

where $\mathbf{w}_{j k}$ is a vector of explanatory variables defined at the school or LEA level, $\boldsymbol{\gamma}$ is a vector of coefficients, and $u_{j k}^{(z)}$ and $v_{k}^{(z)}$ are school and LEA level residuals.

Equations (1) and (2) define a simultaneous equations model. The equations are linked via the school and LEA residuals and must therefore be estimated jointly. At each level, we assume that the residuals follow bivariate normal distributions, i.e. $\mathbf{u}_{j k}=\left[\begin{array}{ll}u_{j k}^{(y)} & u_{j k}^{(z)}\end{array}\right]^{T} \sim N_{2}\left(\mathbf{0}, \boldsymbol{\Omega}_{u}\right)$ and $\quad \mathbf{v}_{k}=\left[\begin{array}{cc}v_{k}^{(y)} & v_{k}^{(z)}\end{array}\right]^{T} \sim N_{2}\left(\mathbf{0}, \boldsymbol{\Omega}_{v}\right) . \quad$ We denote the 
covariances at the school and LEA level by $\sigma_{u}^{(y z)}$ and $\sigma_{v}^{(y z)}$ respectively. Likelihood ratio tests may be used to test whether either $\sigma_{u}^{(y z)}$ or $\sigma_{v}^{(y z)}$, or both, equal zero. A covariance that is significantly different from zero implies that $z_{j k}$ is endogenous, and the nature of the selection effect is given by the direction of the covariance estimate.

\subsubsection{Identification}

In order to identify the simultaneous equations model (1) and (2), the vector $\mathbf{w}_{j k}$ must contain at least one variable, called an instrument, which is not contained in $\mathbf{x}_{i j k}$. To qualify as an instrument, a variable must predict the allocation of resources across schools, but should not have a direct effect on attainment.

Finding adequate instruments in this area of research is quite problematic (Burtless, 1996). Given that school funding varies by LEA, and that LEAs are subject to political control, the political party in control of the local authority is one potential instrument. We argue that political control of the local authority will affect educational spending in that LEA but will not directly impact on pupil achievement. The first instrument is therefore a variable indicating the political control of the local authority, i.e. whether Labour, Conservative, Liberal or other (including no overall political control by one party). As can be seen in Figure 1, the mean raw expenditure per student is highest in Liberal and Labour controlled local education authorities, and lowest in Conservative controlled authorities.

It is possible that residents who place greater emphasis on education (and hence whose children tend to do better in school) will vote for parties that advocate higher educational spending. However, residents vote for a party that has policies on a number of different issues, not just educational spending. It is not clear that residents will vote purely, or even primarily, on the basis of parties' educational spending plans, especially as in the UK local 
elections are generally dominated by national politics. It is therefore unlikely that educational spending is a major issue in most local elections.

Our second instrument is lagged school size, which is an instrument that has been used by others in the field (Iacovou, 2002). School size (in terms of pupil numbers) is a key factor predicting the per capita level of funding in a school. The correlation between lagged school size and expenditure per student is -0.30 and significant at the $5 \%$ level. The correlation between lagged school size and the student teacher ratio is +0.11 and significant at the $5 \%$ level.

Of course for school size to be an adequate instrument it must not impact directly on pupil achievement. There is little evidence that school size has an effect on pupil achievement, at least not in studies that use rich pupil level data such as the NPBD. An argument can be made that more effective schools tend to be bigger because they attract more pupils, thereby causing a positive relationship between school size and pupil achievement. However, in our data we are able to control for this to some extent by including an indicator of how popular and 'full' the school is ${ }^{5}$. As a further robustness check, we also re-estimated our models using lagged school capacity, rather than lagged school size. This was on the grounds that school capacity is simply a function of the physical construction of the school, unrelated to current student enrolment. There is little change in the results when this alternative instrumental variable is used.

\subsubsection{Estimation}

\footnotetext{
${ }^{5}$ That is the school's percentage capacity utilization, which is the actual number of students in years 7-11 compared to the maximum physical capacity in terms of student numbers, which is determined by the Department for Education and Skills.
} 
The simultaneous equations model can be framed as a multilevel bivariate response model. For each individual, we can define a bivariate response $y_{r i j k}(r=1,2)$ where $y_{1 i j k}=y_{i j k}$ and $y_{2 i j k}=z_{j k}$. In addition, we define two response indicators as follows:

$$
I_{r i j k}^{(y)}=\left\{\begin{array}{ll}
1 & \text { if } y_{r i j k}=y_{i j k} \\
0 & \text { if } y_{r i j k}=z_{j k}
\end{array}, \quad I_{r i j k}^{(z)}=1-I_{r i j k}^{(y)}\right.
$$

Equations (1) and (2) can then be written in the form of a single equation for the stacked responses $\left\{y_{\text {rijk }}\right\}$ as

$$
\begin{aligned}
y_{r i j k}= & \boldsymbol{\alpha}^{T} \mathbf{x}_{i j k} I_{r i j k}^{(y)}+\beta z_{j k} I_{r i j k}^{(y)}+v_{k}^{(y)} I_{r i j k}^{(y)}+u_{j k}^{(y)} I_{r i j k}^{(y)}+e_{i j k} I_{r i j k}^{(y)} \\
& +\gamma^{T} \mathbf{w}_{j k} I_{r i j k}^{(z)}+v_{k}^{(z)} I_{r i j k}^{(z)}+u_{j k}^{(z)} I_{r i j k}^{(z)}
\end{aligned}
$$

In the standard bivariate model, both responses are at the individual level and therefore the bivariate response vector will be of length $2 n$ (Goldstein, 2003; Chapter 6). In the present case, however, the responses are defined at different levels of the hierarchy: $y_{i j k}$ is a studentlevel response, while $z_{j k}$ is at the school level. While we could replicate values of $z_{j k}$ for students in the same school, it is more computationally efficient to restructure the data so that there is a single observation of $z_{j k}$ for each school, leading to a response vector of length $n+J$. The explanatory variables in (3) are the two-way interactions between $I_{\text {rijk }}^{(y)}$ and each element of $\left[\begin{array}{ll}\mathbf{x}_{i j k}^{T} & Z_{j k}\end{array}\right]$, and between $I_{r i j k}^{(z)}$ and the elements of $\mathbf{w}_{j k}^{T}$. The random effects in the attainment and resource equations are fitted by allowing the coefficient of $I_{\text {rijk }}^{(y)}$ to vary across students, schools and LEAs, and the coefficient of $I_{\text {rijk }}^{(z)}$ to vary across schools and LEAs.

We estimated model (3) using MLwiN v2.0 (Rasbash et al., 2004).

\section{Data}

The data for this paper come largely from the NPDB. PLASC contains school characteristics (size, type, pupil-teacher ratio etc.), pupil characteristics (age, gender, ethnicity, eligibility for 
free school meals etc.) and pupil achievement data at each key stage of the curriculum (ages 7, 11, 14 and 16). We merged into these data additional information on school expenditure and political control of the local authority, as well as Census information on the socioeconomic characteristics of each child's neighbourhood.

Our model estimates the impact of school resources on pupil achievement in English, mathematics and science at age 14, i.e. Key Stage 3 in 2002/3. This consists of a sample of 430,000 pupils. We control for each pupil's prior achievement at Key Stage 2 (age 11), i.e. in 1999/2000. The dependent variables are continuous test scores, which vary from 0 to almost 9 for maths, and from 0 up to almost 8 for science and English.

The resource variables we use are all at school level, namely expenditure per student ${ }^{6}$, the average student teacher ratio in the school and the ratio of students to non-teaching staff. The resource variables were averaged over the three years that the sample was in secondary school. We estimated separate models for the expenditure and the staffing resource variables, since the majority of school spending is on teachers. Teacher salary costs are on average 61 per cent of secondary schools' expenditure (OFSTED, 2003). If expenditure per pupil and the pupil-teacher ratio are included in the same model, then the effect of the pupil-teacher ratio is biased downwards because a lower pupil-teacher ratio for a given level of spending automatically implies that there are less resources available for other inputs (Todd and Wolpin, 2003).

Full descriptive statistics are given in Table 1.

\footnotetext{
${ }^{6}$ Deflated by an indicator of the cost of living in the area, namely the Area Cost Adjustment.
} 


\section{Results}

We begin by examining the extent to which student attainment scores are clustered within schools and LEAs, and school resources are clustered within LEAs. Table 2 shows estimates of the residual variance at each level, from which estimates of the intra-school and intra-LEA correlations have been calculated. The estimates for attainment are from estimating separate three-level models for attainment at age 14 in maths, science and English, adjusting for attainment at age 11 in the same subjects. Thus the variance components represent the variance at each level in progress from entry into secondary school up to age 14 . The estimates for school resources are from fitting separate two-level models to the expenditure and staffing measures. At this stage of the analysis, no student or school characteristics have been included in any of the models.

The intra-school correlations for attainment show that there are moderate school effects on performance in all three subjects, with the strongest effect on English scores: $22 \%$ of the total variance in English progress is due to differences between schools. After taking into account school effects on progress, LEA effects are very weak. Turning to the school resource measures, we find that $19 \%$ of the total variance in expenditure per student can be explained by differences between LEAs. This moderately high intra-LEA correlation implies that while LEAs vary in their mean expenditure per student (averaging across all schools in an LEA), there is similarity in the expenditure of schools in the same LEA. There is rather less homogeneity within LEAs in pupil-teacher ratios. This is a reflection of the fact that, whilst overall per student spending in each school is determined at LEA level, schools themselves have much more discretion over how this money is spent, and in particular they have some control over the pupil-teacher ratio in each class and year in the school.

We next consider the evidence for the endogeneity of school resources with respect to student attainment. Table 3 shows the results from likelihood ratio tests comparing, for each subject and resource measure, a standard multilevel model and a simultaneous equation model. All models include a number of controls for student background and school characteristics, as described in Section 4. In the standard model, the covariances between the school and LEA residuals across the attainment and resource equations are constrained to equal zero, while in the simultaneous equation model these covariances are freely estimated. Thus we are testing 
the null hypothesis that $\sigma_{u}^{(y z)}=\sigma_{v}^{(y z)}=0$, which is a test of the exogeneity of the relationship between attainment and resources. Rejection of the null implies that school resources are endogenous to attainment, in which case estimates of the impact of resources on attainment from the standard multilevel model will be biased. We find strong evidence that both per student expenditure and the pupil-teacher ratio are endogenous to attainment in science. There is also evidence that staffing and, at the $10 \%$ level, expenditure are endogenous to maths attainment. We conclude, however, that both resource variables are exogenous to English attainment.

Having established that both of our school resource indicators are endogenous to attainment in maths and science, we can examine estimates of the residual correlations to assess the direction of selection effects and whether they operate at the school or LEA level or both. The correlation at the LEA level is interpreted as the (residual) association between the LEA mean level of resources (expenditure or staffing) and LEA mean attainment. A strong correlation at this level would suggest a selection effect that is driven by the way in which central government allocates resources to local authorities. The residual correlation at the school level measures the within-LEA association between school resources and school mean attainment. A strong correlation at the school level implies a selection effect that is due to the nature of resource allocation among schools within an LEA, i.e. non-random allocation within LEAs. A dominant LEA-level correlation would suggest that selection is largely the result of central government policy and political choice at local level, as Conservative LEAs tend to be lower spending authorities.

Table 4 shows estimates of the correlation between the school and LEA residuals across the resource and attainment equations in the simultaneous equation model. We discuss only the interpretation of the correlations between resources and attainment in maths and science, since exogeneity tests (Table 3 ) suggest that resources may be assumed exogenous to English scores. The school and LEA-level correlations between the residuals for expenditure per student and attainment in maths and science are negative; these correlations are strongest for science and, for both subjects, the LEA-level correlation is the largest. A negative correlation at the LEA level implies that unobserved LEA factors influencing school expenditure are negatively correlated with the unobserved LEA-level determinants of student attainment. Equivalently we may conclude that, even after controlling for a rich set of explanatory 
variables, there is a negative association between the mean level of expenditure in an LEA and the LEA mean attainment. A negative selection effect is consistent with the policy of compensatory funding where schools with greater learning needs receive more funding per student (see Section 2). The evidence suggests that the selection effect is stronger at the LEA level, which is as one would expect, given that the expenditure for education that is notionally allocated to each LEA (the education Standard Spending Assessment discussed in Section 2) is determined by central government on the basis of a formula that explicitly includes many factors likely to be highly correlated with pupil attainment. For example, central government takes the following factors into account when determining the level of each LEA's education SSA: the proportion of immigrants in the area, the proportion of the resident population on benefits and indicators of deprivation. The selection effect is greatest for science, particularly at LEA level. It appears that the socio-economic factors that determine each LEA's allocation for expenditure on education are also more highly correlated with science achievement. Further investigation is required as to why this might be the case but our results clearly indicate that resourcing effects vary across subjects.

The residual correlations between maths and science attainment and the pupil-teacher ratio follow a similar pattern to those for attainment and expenditure, although the correlations are now positive because a high pupil-teacher ratio is an indicator of lower resources. However, the correlations at both levels are stronger than for expenditure, particularly at the school level. The fact that the selection effect is greater for the pupil-teacher ratio, as compared to expenditure, indicates that there is more autonomy for schools to determine how they spend their resources. The large positive selection effect is consistent with the widely held view that education professionals tend to allocate poorer performing students into smaller class sizes. This phenomenon may also occur at LEA and school level, whereby schools with lower performing pupils either are allocated or opt for lower pupil teacher ratios. This would come about by LEAs systematically attempting to reduce the pupil-teacher ratio in their most disadvantaged schools and by schools with disadvantaged pupils opting to have a lower pupil-teacher ratio for a given level of expenditure, as compared to their more prosperous counterparts.

In Table 5, we demonstrate the impact of adjusting for endogeneity on estimates of the effects of school resources on student attainment. For each subject and resource indicator, standardised coefficients are presented for two models: the standard multilevel model 
denoted in (1), which assumes that resources are exogenous, and the simultaneous equation model denoted jointly by (1) and (2), which allows for endogenous resource effects. Based on the results from either model, we would predict a statistically significant, though small, improvement in students' maths and science progress for an increase in the expenditure per student or a decrease in the pupil-teacher ratio, et ceteris paribus. When we allow for endogeneity, however, the magnitude of these effects increases substantially. The increase in effect size is expected due the nature of selection implied by the direction of the residual correlations between resources and attainment (Table 4).

To assess the effects of school resources on English attainment, we may interpret the estimates from the standard multilevel model due to the lack of significance of the residual correlations in the simultaneous equation model (Table 3). We find a counter-intuitive negative effect of expenditure per student on English progress, and no significant effect of the pupil-teacher ratio. It has been suggested that the school environment has a lesser effect on progress in English than in other subjects, partly because the home environment is relatively more important in determining language development. This might explain why the pupilteacher ratio does not have a significant impact on pupil progress in English, particularly at the relative low levels of pupil-teacher ratio found in the English education system (relative to world standards). However, it does not explain why expenditure might be negatively related to English progress.

\section{Discussion}

This paper has adopted a multilevel simultaneous equation modelling approach to determine the impact of school resources on pupil attainment at age 14. The primary objective of the paper was to determine whether additional expenditure on education would lead to improved pupil attainment, clearly an important issue for policy makers attempting to raise standards in education and improve the performance of low achieving groups. The paper, building on previous work using an instrumental variable approach (Levačić et al., 2005) addresses a number of methodological difficulties in this literature, in particular the endogeneity of school resource levels, and the intra-school correlations in student responses.

In policy terms our results suggest the following. Firstly, additional resources do have a 
positive impact on attainment in mathematics and science but not for English ${ }^{7}$. These positive resource effects are particularly strong once we account for the endogeneity of school resources, i.e. once we allow for the fact that in the UK education system more resources are systematically allocated to LEAs and schools that have lower attaining pupils. From a policy perspective, this suggests that better funded schools, and those with lower pupil-teacher ratios, have higher pupil attainment ceteris paribus than schools with lower levels of resources. The magnitude of the effects suggests that policies to reduce pupil-teacher ratios in secondary schools may be particularly effective, but again only for improving pupil attainment in science and mathematics. Comfortingly, from a policy perspective, this suggests that schools do use resources efficiently, at least to some extent, in that we find a systematic positive relationship between resource inputs and pupil outcomes for science and mathematics. However, we find insignificant or even negative resource effects for English. In other words, we find no evidence that schools and LEAs that have higher levels of expenditure per pupil and lower pupil-teacher ratios have better pupil attainment in English. This might imply that schools are not efficient in their use of resources in English. However, an alternative possibility is that family background and home environment plays a more important role in determining attainment in English, and that we are unable to fully model this process in our data. This latter suggestion is conjecture at this point and the issue clearly merits further research. An alternative suggestion is that the KS3 English tests are a poorer measure of students' 'real' attainment in English than in science and maths. There is some support for this from the fact that English KS3 is not as well predicted by English KS2, as are Maths and science at KS3 by their respective subjects at KS2. The first strong methodological message from this paper is that any analysis of the relationship between school resources and pupil attainment needs to allow fully for both variation in resource effects across different subjects and for the endogeneity of resource allocation. The magnitude of the resource effects is considerably larger once endogeneity is allowed for, indicating that studies that do not allow for endogeneity will have estimates that are biased downwards.

The paper also makes another important methodological contribution to the literature. Generally the standard instrumental variable method used in this literature to overcome the

\footnotetext{
${ }^{7}$ As has already been discussed a related and important policy question is how the impact of additional resources on educational attainment may differ across different types of student, e.g. those from lower socioeconomic backgrounds, different ethnic groups and such like. These questions are addressed in Levačić et al. (2005).
} 
endogeneity of school resources, assumes that any selection bias is operating at the lowest level of observation. In this paper we allow for selection at both the level of the school and the level of the LEA. In the analysis this turns out to be important as there is selection at both LEA and school level. Furthermore, the extent of the selection bias varies by subject and by the nature of the resource variable being considered. Specifically, the school and LEA-level correlations between the residuals for expenditure per student and attainment in maths and science are negative, are particularly strong for science and are larger at the LEA-level. What this result implies is that resource allocation in the UK education system is compensatory, i.e. disadvantaged schools and LEAs have higher levels of spending. Furthermore, there is strong selection at the LEA level, reflecting the fact that central government determines the amount allocated to each LEA to spend on education on the basis of a number of socio-economic indicators of disadvantage, many of which are also negatively correlated with pupil attainment. In terms of the pupil-teacher ratio, the correlations at both school and LEA level are stronger than for expenditure, particularly at the school level. The fact that the selection effect is greater for the pupil-teacher ratio is explained by the fact that schools themselves have much discretion over how this money is spent and disadvantaged schools may be more likely to use their expenditure to reduce their pupil-teacher ratio. In conclusion, in models that do not allow for this endogeneity, or only allow for selection at the level of the school, an important source of selection bias will be ignored.

\section{References}

Angrist, J., \& Lavy, V. (1999). Using Maimonides' rule to estimate the effects of class size on scholastic achievement. Quarterly Journal of Economics 114 (2), 533-575.

Burtless, G. (Ed.) (1996). Does Money Matter? The effect of school resources on student achievement and adult success. Washington, D.C., The Brookings Institution.

Coleman, J. S., Campbell, E. Q., Hobson, C. J., McPartland, J., Mood, A. M., Weinfeld, F. D., \& York, R. L. (1966). Equality of Educational Opportunity. Washington DC, Government Printing Office.

Dearden, L., Ferri, J., \& Meghir, C. (2001). The effects of school quality on educational 
attainment and wages. Review of Economics and Statistics 84 (1), 1-20.

Dobbelsteen, S., Levin, J., \& Oosterbeek, H. (2002). The causal effect of class size on scholastic achievement: distinguishing the pure class size effect from the effect of changes in class composition. Oxford Bulletin of Economics and Statistics 64 (1), 17-38.

Dolton, P., \& Vignoles, A. (2000). The effects of school quality on pupil outcomes: an overview. In: H. Heijke (Ed.), Education, Training and Employment in the Knowledge-Based Economy (36-52). Basingstoke: Macmillan.

Dustmann, C., Rajah, N., \& van Soest, A. (2003). Class size, education and wages. The Economic Journal 113 (485), F99-F120.

Goldstein, H. (2003) Multilevel Statistical Models. $3^{\text {rd }}$ edition. London: Arnold.

Hakkinen, I., Kirjavainen, T., \& Uusitalo, R. (2003). School resources and student achievement revisited: new evidence from panel data. Economics of Education Review 22, 329-335.

Hanushek, E. A. (1997). Assessing the effects of school resources on student performance: an update. Education Evaluation and Policy Analysis 19 (2), 141-164.

Hoxby, C. M. (2000). The effects of class size on student achievement: new evidence from population variation. The Quarterly Journal of Economics (November), 1239-1285.

Iacovou, M. (2002). Class size in the early years: is smaller really better? Education Economics 10 (3), 261-290.

Jepsen, C., \& Rivkin, S. (2002). What is the trade off between smaller classes and teacher quality? NBER Working Paper 9205.

Krueger, A. (2003). Economic considerations and class size. Economic Journal 113 (485), 34-63. 
Krueger, A., \& Whitmore, D. M. (2001). The effect of attending small classes in the early grades of college-test taking and middle school test results: evidence from Project STAR. The Economic Journal 111 (468), 1-28.

Laine, R. D., Greenwald, R., \& Hedges, L. V. (1996). Money does matter: a research synthesis of a new universe of education production function studies: In L. O. Picus, \& J. L. Wattenbarger (Eds), Where Does the Money Go? Resource allocation in elementary and secondary schools (pp. 44-70). Thousand Oaks, Ca: Corwin Press.

Levačić, R., Jenkins, A., Vignoles, A. and Allen, R. (2005) The effect of school resources on student attainment in English secondary schools, forthcoming CEE Discussion Paper.

Levačić, R., \& Vignoles, A. (2002). Researching the links between school resources and student outcomes in the UK: a review of issues and evidence. Education Economics 10 (3), 312-331.

OECD (2004) Education at a Glance, Paris: OECD.

OFSTED (2003). National Summary Data Report for Secondary Schools Data 2003 data version 1. London: OFSTED www.ofsted.gov.uk/public/docs01.

Rasbash, J., Steele, F., Browne, W. and Prosser, B. (2004) A User's Guide to MLwiN version 2.0. London: Institute of Education, University of London.

Todd, P., \& Wolpin, K. (2003). On the specification and estimation of the production function for cognitive achievement. The Economic Journal 113 (485), 3-33.

Wilson, K. (2000). Using the PSID to study the effects of school spending. Public Finance Review 28 (5), 428-451. 
Figure 1: Mean expenditure per pupil by political control of the local authorities

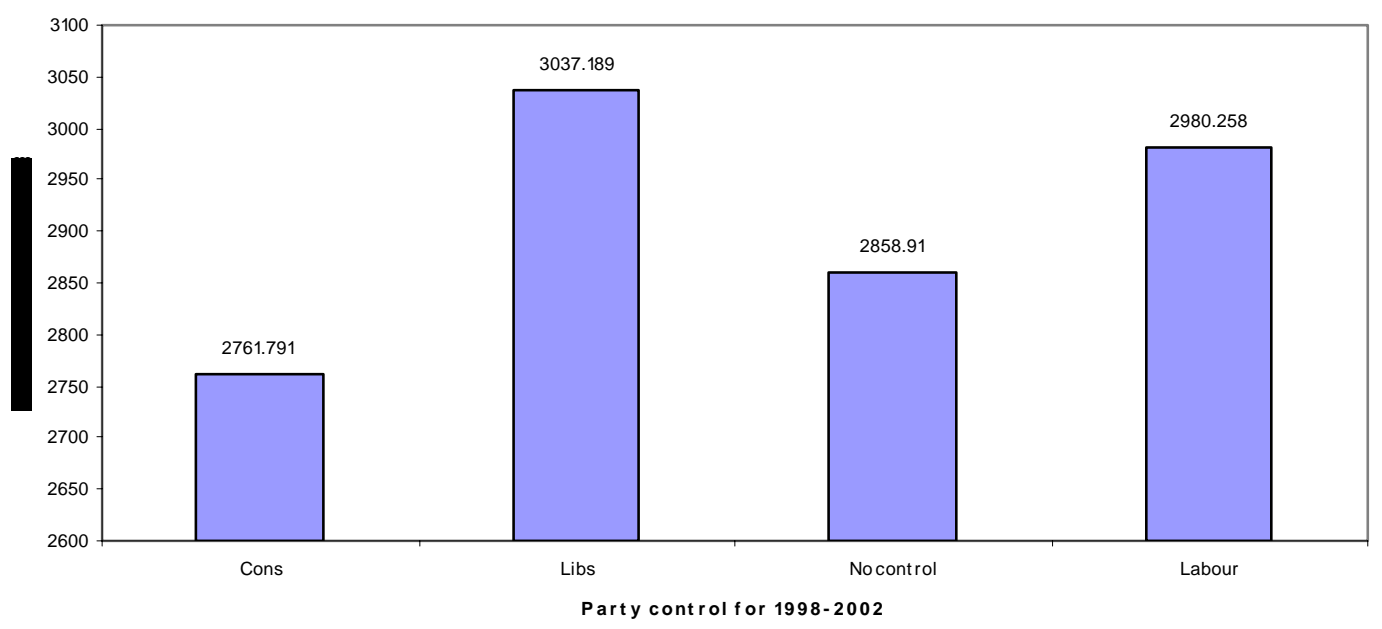


Table 1. Descriptive statistics for attainment at age 14, school resource measures and instruments

\begin{tabular}{lrrrrr}
\hline & n & Mean & Std. Dev. & Min & Max \\
\hline Student-level variables (2003) & & & & & \\
Key Stage 3 Maths score & 464783 & 6.03 & 1.22 & 0.14 & 8.96 \\
Key Stage 3 Science score & 464783 & 5.73 & 1.02 & 0.00 & 7.96 \\
Key Stage 3 English score & 464783 & 5.59 & 1.10 & 0.00 & 7.97 \\
Key Stage 2 Maths score & 464783 & 4.49 & 0.76 & 0.10 & 7.00 \\
Key Stage 2 Science score & 464783 & 4.76 & 0.58 & 0.10 & 6.78 \\
Key Stage 2 English score & 464783 & 4.52 & 0.67 & 0.00 & 6.89 \\
School-Level Variables & & & & & \\
No of FTE Students (averaged)* & 3011 & 1007.97 & 334.24 & 51.67 & 2402.33 \\
No of FTE Students, lagged (1999) & 3277 & 909.05 & 342.27 & 104.00 & 2361.00 \\
Capacity utilisation (averaged)* & 2994 & 0.98 & 0.15 & 0.33 & 2.50 \\
Staffing variables & & & & & \\
Student/teacher ratio (averaged)* & 3003 & 16.44 & 1.28 & 10.49 & 21.42 \\
Non-teaching staff per student (averaged)* & 3011 & 56.10 & 16.74 & 8.35 & 161.42 \\
Financial variables & & & & & \\
Expenditure per student (averaged)* & 3011 & 2969.72 & 416.43 & 2053.60 & 10828.75 \\
& & & & & \\
Party in control of LEA & $\mathbf{1 9 9 8}(\mathbf{\%})$ & $\mathbf{1 9 9 9}(\mathbf{\% )}$ & $\mathbf{2 0 0 0}(\mathbf{\%})$ & $\mathbf{2 0 0 1}(\mathbf{\%})$ & $\mathbf{2 0 0 2}(\mathbf{\%})$ \\
Conservative & 11.0 & 10.3 & 13.7 & 19.2 & 21.9 \\
Labour & 58.2 & 57.5 & 50.0 & 49.3 & 45.2 \\
Liberal Democrats & 6.2 & 7.5 & 7.5 & 5.5 & 4.8 \\
No overall control & 24.7 & 24.7 & 28.8 & 26.0 & 28.1 \\
\hline n & 146 & 146 & 146 & 146 & 146 \\
\hline
\end{tabular}

*Variables are averaged over 2000/01 to 2002/03. 
Table 2. Variance components and intra-class correlations for student attainment at age 14 and school resources

\begin{tabular}{|c|c|c|c|c|c|c|}
\hline & \multicolumn{6}{|c|}{ Student attainment in ... } \\
\hline & \multicolumn{2}{|c|}{ Maths } & \multicolumn{2}{|c|}{ Science } & \multicolumn{2}{|c|}{ English } \\
\hline & Est. & (SE) & Est. & (SE) & Est. & (SE) \\
\hline \multicolumn{7}{|l|}{ Student attainment } \\
\hline Between LEA & 0.009 & $(0.001)$ & 0.012 & $(0.002)$ & 0.004 & $(0.001)$ \\
\hline Between school, within LEA & 0.029 & $(0.001)$ & 0.034 & $(0.001)$ & 0.089 & $(0.002)$ \\
\hline Between student, within school & 0.212 & $(0.000)$ & 0.283 & $(0.001)$ & 0.330 & $(0.001)$ \\
\hline Intra-LEA correlation & 0.036 & - & 0.036 & - & 0.009 & - \\
\hline \multirow[t]{3}{*}{ Intra-school correlation } & 0.152 & - & 0.140 & - & 0.220 & - \\
\hline & \multicolumn{6}{|c|}{ School resource variables } \\
\hline & Est. & (SE) & & & & \\
\hline \multicolumn{7}{|l|}{ Expenditure per student } \\
\hline Between LEA & 0.202 & $(0.030)$ & & & & \\
\hline Between school, within LEA & 0.842 & $(0.022)$ & & & & \\
\hline Intra-LEA correlation & 0.193 & - & & & & \\
\hline \multicolumn{7}{|l|}{ Pupil-teacher ratio } \\
\hline Between LEA & 0.095 & $(0.018)$ & & & & \\
\hline Between school, within LEA & 0.935 & $(0.024)$ & & & & \\
\hline Intra-LEA correlation & 0.092 & - & & & & \\
\hline
\end{tabular}

Notes: (1) Attainment and resource variables have been standardised; (2) All estimates are from fitting separate multilevel models for attainment and school resources; (3) Estimates for attainment are adjusted for prior attainment (age 11 subject scores) and therefore represent variance in progress between ages 11 and 14 . 
Table 3. Results from likelihood ratio tests of the exogeneity of school resource variables by subject

\begin{tabular}{llll}
\hline & Maths & Science & English \\
\hline Expenditure per student & 4.9 & 27.5 & 0.8 \\
& $\mathrm{p}=0.086$ & $\mathrm{p}<0.001$ & $\mathrm{p}=0.670$ \\
\hline Pupil-teacher ratio & 8.4 & 30.7 & 0.4 \\
& $\mathrm{p}=0.015$ & $\mathrm{p}<0.001$ & $\mathrm{p}=0.819$ \\
\hline
\end{tabular}

Note: Figures in each cell are the likelihood ratio test statistic and p-value. Each test is based on 2 degrees of freedom. 
Table 4. Covariances (and correlations) between LEA and school level random effects across simultaneous equations for student attainment and school resources

\begin{tabular}{llll}
\hline & \multicolumn{2}{l}{ Student attainment at age 14 } \\
\cline { 2 - 4 } & Maths & Science & English \\
\cline { 2 - 4 } & Cov (SE) & Cov (SE) & Cov (SE) \\
& Corr & Corr & Corr \\
\hline Expenditure per student & & & \\
\hline LEA level & $-0.0048(0.0017)$ & $-0.0114(0.0024)$ & $0.0031(0.0025)$ \\
& $\mathbf{- 0 . 3 5 4}$ & $\mathbf{- 0 . 6 0 8}$ & $\mathbf{0 . 2 0 6}$ \\
\hline School level & $-0.0066(0.0014)$ & $-0.0221(0.0017)$ & $0.0011(0.0030)$ \\
& $\mathbf{- 0 . 0 9 5}$ & $\mathbf{- 0 . 2 6 9}$ & $\mathbf{0 . 0 0 7}$ \\
\hline Pupil-teacher ratio & & & $-0.0024(0.0025)$ \\
\hline LEA level & & & $\mathbf{- 0 . 1 6 9}$ \\
\hline School level & $0.0076(0.0019)$ & $0.0134(0.0027)$ & $\mathbf{- 0 . 0 0 2 7 ( 0 . 0 0 3 9 )}$ \\
& $\mathbf{0 . 5 3 9}$ & $\mathbf{0 . 7 0 3}$ & $\mathbf{- 0 . 0 1 3}$ \\
\hline
\end{tabular}

Notes: (1) Estimates are from fitting six separate simultaneous equation models, for student attainment in each subject paired with a school resource variable; (2) All models include a range of student (in the attainment equations), school and LEA characteristics (see Appendix for details). 
Table 5. Estimated effects of school resources on student attainment at age 14

\begin{tabular}{|c|c|c|c|c|}
\hline & \multicolumn{2}{|c|}{ Standard multilevel } & \multicolumn{2}{|c|}{ Simultaneous equations } \\
\hline & Est. & (SE) & Est. & (SE) \\
\hline \multicolumn{5}{|c|}{ Expenditure per student } \\
\hline Maths & 0.0073 & $(0.0040)$ & 0.0244 & $(0.0040)$ \\
\hline Science & 0.0069 & $(0.0046)$ & 0.0663 & $(0.0046)$ \\
\hline English & -0.0166 & $(0.0078)$ & -0.0254 & $(0.0078)$ \\
\hline \multicolumn{5}{|c|}{ Pupil-teacher ratio } \\
\hline Maths & -0.0056 & $(0.0030)$ & -0.0462 & $(0.0030)$ \\
\hline Science & -0.0097 & $(0.0034)$ & -0.1126 & $(0.0034)$ \\
\hline English & -0.0040 & $(0.0061)$ & 0.0031 & $(0.0062)$ \\
\hline
\end{tabular}

Notes: (1) Because attainment and resource variables are standardised, coefficients can be interpreted as partial correlations; (2) All estimates are from models that control for a range of student, school and LEA characteristics (see Appendix for details), including age 11 subject scores. 